\title{
Mandela líder maior de uma geração de Pan-africanismo Libertário
}

\section{Renata Aquino da Silva}

Doutoranda em Educação - Universidade Federal do Ceará (UFC), Fortaleza, Brasil, mestre em Educação - Universidade do Estado do Rio de Janeiro (UERJ), especialista em Linguística Aplicada - Universidade do Estado do Rio de Janeiro (UFRJ) e licenciada em Letras - UFRJ

\section{Henrique Cunha Júnior}

Professor Titular da Universidade Federal do Ceará, Fortaleza, Brasil, desde 1995. Tese de Livre docente USP - 1993. Professor da USP entre 1985 - 1994. Pesquisador Sênior do IPT - 1988 - 1994. Doutor pelo Instituto Nacional Pesquisa de Lorraine - INPL.

\section{Resumo}

Este artigo aborda Nelson Mandela como um líder praticante das ideias do pan-africanismo, das filosofias africanas e dos pensamentos políticos, propondo uma reflexão sobre a autoctonia dos povos africanos e o combate ao eurocentrismo e à dominação ocidental. Madiba, liderança que difundiu ideias que implicaram a responsabilidade com paz e do bem estar à espécime humana, defendeu a população negra como parte de uma identidade cultural, política, econômica e social de povos que vivem ou são originárias do continente africano.

Palavras-chave: Mandela, pan-africanismo libertário, unidade cultural africana.

\section{Resumen}

Este artículo aborda Nelson Mandela, como practicante principal de las ideas del panafricanismo, filosofías africanas y pensamientos políticos, proponiendo una reflexión sobre los pueblos de África y la lucha contra el eurocentrismo y la dominación occidental. Madiba, las ideas de liderazgo que se propagan a la responsabilidad implícita con la paz y el bienestar de espécimen humano, defendió la población negro como parte de una identidad cultural, política, económica y social que viven o proceden del continente africano.

Palabras clave: Mandela, libertario panafricanismo, la unidad cultural africana.

\section{Abstract}

This article discusses Nelson Mandela, as a leading practitioner of the ideas of Pan-Africanism, African philosophies and political thoughts, proposing a reflection on the autochthonous peoples of Africa and the fight against Eu- 
rocentrism and Western domination. Madiba, leadership ideas that spread implied responsibility with peace and welfare of human specimen, defended the black population as part of a cultural, political, economic and social people who live or originate from the African continent.

Keywords: Mandela, libertarian pan-Africanism, African cultural unity. 


\section{0 século das proposições libertárias dos povos africanos}

constituição do mundo do capitalismo ocidental tem vários matizes e ver-
sões segundo os povos e as suas formas de vida, além das suas experiências
históricas específicas. Entendemos que não existe a possibilidade de uma história universal da humanidade, pois as especificidades são várias e as formas de interpretações das histórias humanas bastante diversas.

Para as populações africanas e descendentes, o mundo é entendido por meio dos valores civilizatórios africanos, em que a existência humana é parte de um todo. Nessa concepção, a ancestralidade é um contínuo entre o passado, o presente e o futuro, em que todos os seres da natureza são interdependentes. Trata-se de uma visão diferente da ideia de individualidade, existe somente a coletividade - existência mútua e a preservação da vida como parte da responsabilidade contínua dos seres humanos.

Passado distante é o ancestral mais antigo, aquele que produziu o passado em que nasceram as transformações que duram até hoje. $\mathrm{O}$ passado recente é aquele que nossos avós produziram e, no desacordo e no desequilíbrio, podem ter produzindo catástrofes. Temos o presente, os lugares e os períodos que constroem o futuro. Este presente, dos muntu e bantu, que líderes como Mandela produziram que nos cumpre mais que compreendê-lo e sim de produzir um novo futuro, mais igual e justo, compensando os desequilíbrios do passado intermediário. Os Muntu (ser humano) e Bantu (coletivo humano) apresentam uma visão da humanidade que implica uma grande responsabilidade quanto ao seu futuro.

O Ocidente criou uma visão de mundo parcializada, fragmentada, produtora do espírito ideológico da dominação entre povos, gerando as ideias de raças humanas, de povos inferiores e superiores, de civilizações e incivilizações permitindo o escravismo criminoso, baseando-se nas percepções da ciência sistematizada para justificar o mando e impor a violência teorizada pela ciência.

Percepções deturpadas e sustentadas pelo relato de alguns feitos históricos sob uma abordagem científica baseada em pesquisas passadas e reconhecidas dentro do uma pequena comunidade científica, quem sabe, específica. Teorias imersas em dados históricos forjados e narrados de maneira a sustentar paradigmas, que se sedimentam no jogo das relações sociais. Ciência de realizações metonímicas, a parte representando o todo, que nada mais é do que abstração. A ciência tanto abstraiu que transcendeu da possibilidade de investigação para a necessidade de comprovação. De resultados a resultados, de forjamentos a forjamentos, de parcialidades a parcialidades, os paradigmas da ciência apresentaram e ainda apresentam resultados vinculados às ideias que o sustentam, e assim novos paradigmas surgem sem que os anteriores/antigos sejam solucionados. A humanidade é diversa, transformá-la paradigmática é uma anomalia (KUHN, 1987).

As populações africanas e descendentes assim como os seus valores africanos sofrem o peso da brutalidade conceitualizada como raça, a produção da ciência dos séculos 17 e 18 , que deu a fórmula racional da irracionalidade humana. Dos sofrimentos de povos africanos e afrodescendentes nasceram as transformações econômicas que nutriram e nutrem a modernidade e a modernização europeia. $\mathrm{O}$ crime gerou a fortuna do bem-estar ocidental e produziu a ideia de que cultura evoluída era a europeia a ser reproduzida por todos outros povos. 


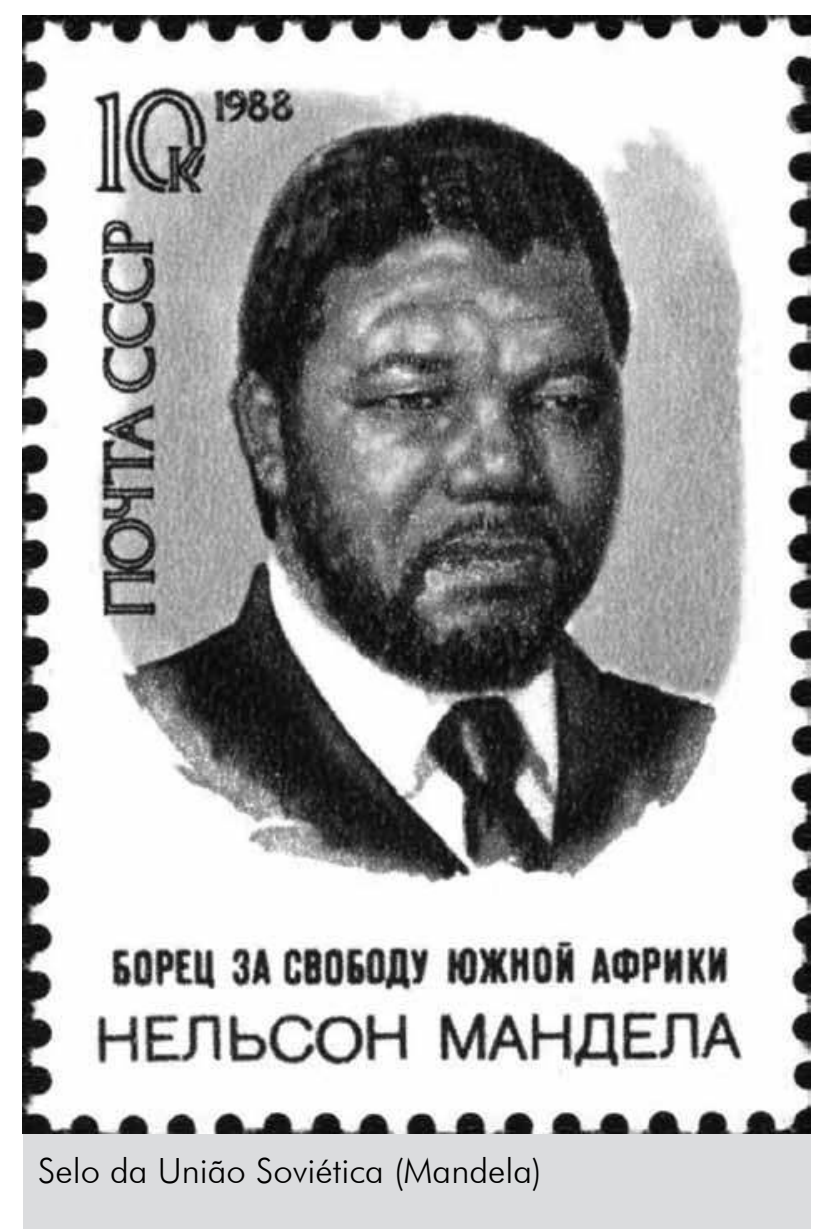

A dominação econômica imposta ao continente africano e uso das forças da cultura religiosa cristã, das fórmulas das organizações políticas europeias, da força das metralhadoras, dos bombardeios e inovações geraram um grande império colonial e produtor de aprimoramento dos sistemas econômicos, culturais, políticos e racionais da política eurocêntrica. $O$ nascimento da modernidade da cultura, considerada esplendorosa, é morte anunciada de tudo que poderia ser pensado como racional fora da ótica eurocêntrica.

Neste artigo, vamos ver a figura de Mandela como um líder praticante das ideias do pan-africanismo e pensando também o enfoque das filosofias africanas e dos pensamentos políticos, propondo a autoctonia dos povos africanos e o combate ao eurocentrismo e à dominação ocidental. Liderança que transcendeu a simples condenação a lutas de classes e à oposição entre possuidora dos bens mateiros e não possuidora, mas na superação das ideias que impliquem a responsabilidade com paz e do bem-estar à espécime humana, independentes da origem da localidade, das histórias particulares, construindo assim um bem comum tal qual o ar e a água que todos bebem e todos respiram. O Bantu que somos, a existência de um nós humano interdependentes e de responsabilidade de todos.

\section{Mandela o símbolo de uma luta}

O pan-africanismo é uma teoria libertária que procura a unidade e a autonomia dos povos africanos e afrodescendentes e o combate à desumanização imposta pelos 
sistemas coloniais e escravistas às populações negras do mundo, compreendendo a população negra como parte de uma identidade cultural, política, econômica e social de povos que vivem ou são originárias do continente africano. A ideia de unidade cultural africana foi pensada e defendida por Cheikh A. Diop que estudou a história do continente africano desde a antiguidade egípcia até nossos dias. Desestabilizou os estudos eurocêntricos sobre o continente africano ao defender que os povos em África seriam de origem egípcia. Diop considera as populações africanas autoras da própria história, desvencilhando os africanos e descendentes da imagem sem história fabricada pela historiografia eurocêntrica.

O continente africano tem origem e cultura importantes nas civilizações do rio Nilo. Por processos migratórios estas culturas se disseminaram e transformaram-se ao longo dos tempos e dos territórios, não obstante, mantendo algumas características civilizatórias que o singularizam, se comparado aos outros continentes. Trata-se de uma base teórica de fundo histórico e não baseada nos conceitos de raças humanas e nem em determinismos históricos, mas na produção e reprodução de uma cultura de formas dinâmicas, existindo avanços e retrocessos, produzindo adaptações às condições ambientais e de períodos históricos, dos círculos de comércio e das relações de poder sobre estas localidades. A unidade cultural é um complemento ao pensamento pan-africanista, uma vez que esta ideia surgiu na segunda metade do século passado. As populações negras na diáspora fazem parte desta unidade cultural africana e produzem a continuidade e as transformações da herança cultural africana nas Américas. Do ponto de vista político e histórico, a unidade cultural africana sela a possibilidade de uma unidade histórica e de identidade dos povos negros no mundo.

O início do pan-africanismo tem origem na diversidade de fatos históricos importantes que partem da revolução haitiana de 1815, em que intelectuais negros já pensavam a importância das populações africanas no mundo e valor das revoluções realizadas por estas populações. A história da revolução do Haiti ficou minimizada devido ao eurocentrismo que se confrontava com a ideia de impossibilidade de um governo negro e a realidade da revolução realizada. Os ex-escravizados e os negros livres, tendo como base um pensamento africano vindo das religiões de base africana, se amolgaram em força revolucionária capaz de derrotar os exércitos franceses de Napoleão. A revolução do Haiti obteve uma divulgação entre as populações negras de todas as Américas. Tornou-se referência de ações contra o escravismo e colonialismo que em diferentes etapas históricas buscaram tornar as populações negras no Haiti livres do trabalho forçoso. Independência e o impacto das ideias do pan-africanismo de libertar-se do lugar imaginado pela ciência dos séculos 18 e 19 culminaram em uma última deslealdade por parte de Simon Bolívar, libertador da Venezuela, refugiado no Haiti - que excluiu a nação que o recebeu do grupo dos países latino-americanos convidados à Conferência do Panamá, em 1826; ainda que o Haiti lhe tenha fornecido proteção, ajuda financeira, dinheiro etc.

Além da revolução do Haiti, existiu também uma contribuição do pensamento do movimento rastafári. Movimento pan-africano reconhecido internacionalmente pelas ideias de repatriação negra, um credo milenar da redenção africana, tradição entendida como uma resistência às estruturas racistas e de dominação. As propostas de Garvey para que olhassem para África refletia propostas de realização pessoal e do grupo que nunca se rendeu às amarras do eurocentrismo. 
Das crenças rastafári se produziu a ideia de um império africano nunca submetido aos europeus. O reino da Etiópia, como também de uma força de retorno das populações de descendentes de africanos à terra prometida. A autonomia econômica e religiosa como resistência e o retorno à África foram as grandes contribuições do pensamento rastafári ao pensamento do pan-africanismo.

Também os movimentos negros para combate aos racismos deram um ângulo de direitos fundamentais e dos direitos civis ao pan-africanismo. Mas as independências das nações africanas produziram a força política dos movimentos do pan-africanismo. Políticos como Kwame Nkrumah e Jonnatas Kenyata produziram as ideias de necessidade de uma unidade política dos países africanos e da autonomia do pensamento africano.

Tivemos como incremento importante do pensamento pan-africano os movimentos literários da negritude e dos seus similares, produzindo um ideal de liberdade e de valorização das culturas e da arte africana.

Em meados do século XX, o pan-africanismo foi explicado como a doutrina política defendida pela irmandade africana, libertação do continente africano de seus colonizadores e o estabelecimento de um Estado que buscasse a unificação de todo o continente sob um governo africano. Alguns teóricos como George Padmore acrescentaram, a partir da Segunda Guerra Mundial, que o governo pan-africano deveria ser gerido segundo as premissas do socialismo científico. Outros teóricos postularam o caminho do rastafarianismo político, que defende um governo essencialmente centrado nos princípios africanos.

Originalmente, o pan-africanismo centrava-se mais sobre a questão racial que no geográfico. Ainda hoje, há muitos que defendem o caminho radicalista, visto os problemas de integração do norte da África, que conta com uma história diferenciada árabe, em uma unidade cultural coerente com a África. Os objetivos do pan-africanismo atual, ainda que sejam semelhantes aos originais, mudaram. Neste sentido, Mandela defendeu estas ideias e cristalizou o símbolo de uma luta internacional e a procura, incitando o mundo a se preocupar com as injustiças impostas pelos sistemas econômicos e políticos ao continente africano e aos africanos da diáspora.

\section{A necessidade de uma avaliação maior dos processos revolucionários}

Nossa existência é definida pela existência de outras existências. Assim, existimos porque os outros existem. No Ubuntu, a existência tem um sentido de coletividade, de colaboração humana. Nesse caminho de colaboração, marca-se a memória do ideal de liberdade defendido pelos movimentos negros. Uma memória de intervenções políticas de intelectuais militantes que defenderam uma postura de existência e de resistência presentes no pan-africanismo, de não sucumbir. Projeto ideológico que tem se constituído como fonte de estudo para pesquisadores que buscaram e ainda buscam diversos mecanismos para inclusão social do negro e superação do racismo e de difusão dos valores africanos.

Os processos revolucionários denunciaram e intervieram nas estratégias de silenciamento e invisibilidade que têm vitimado historicamente as populações que foram associadas à memória africana. Ações que têm uma metodologia fundamental - o pensamento da coletividade e de unidade na diversidade - para a denúncia e reversão do que foi denominado processo civilizador na perspectiva ocidental. No caso do 


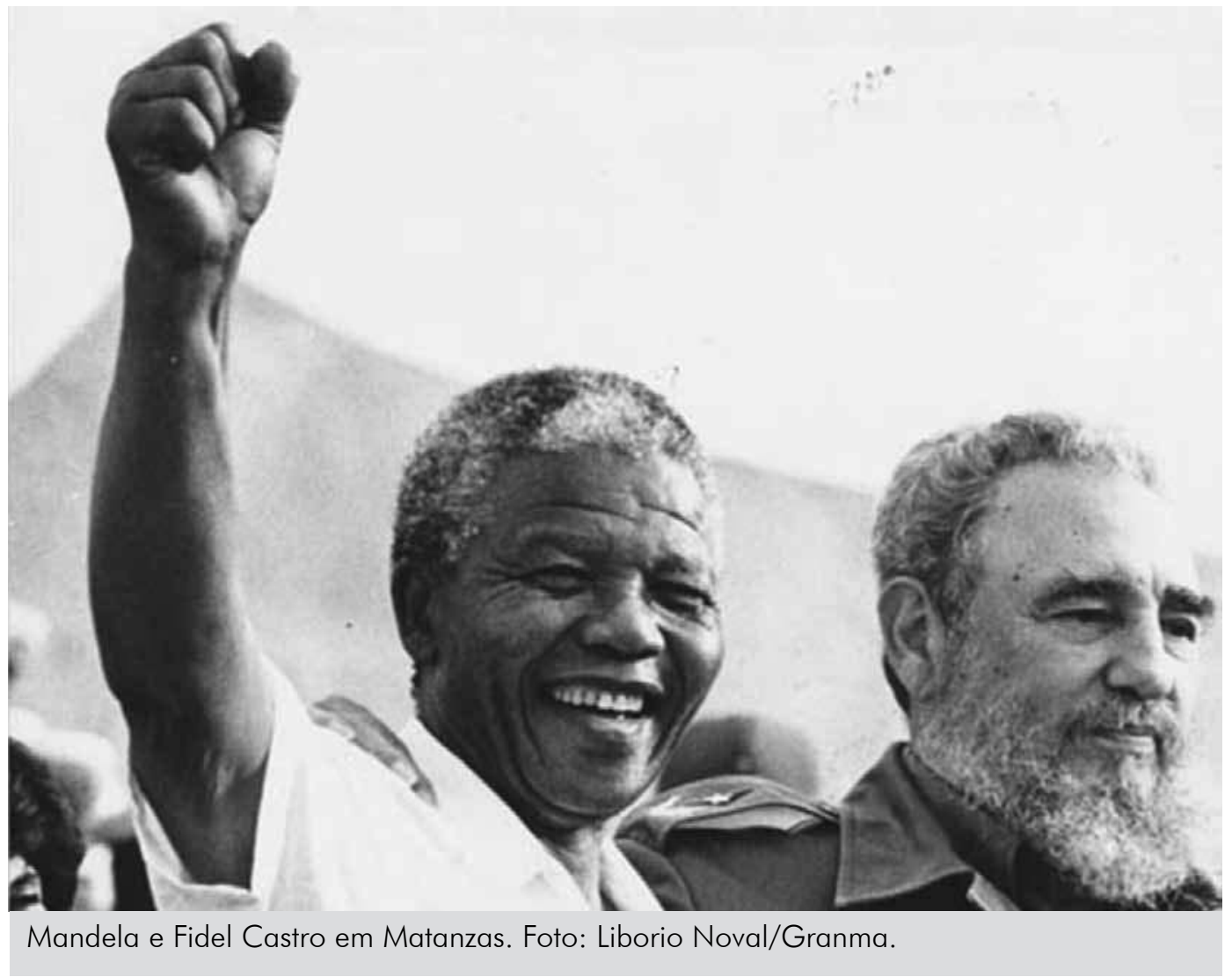

Brasil, desde 2003 é lei ensinar os conhecimentos de base africana, que os conteúdos dos livros didáticos sejam revistos e que o papel do negro na história do Brasil seja reescrito e, por fim, que a literatura negra seja ensinada nas escolas.

Do processo de avaliação dos movimentos revolucionários emerge o fio histórico de que a revolução para reescritura da história das populações negras sempre aconteceu seja pela religião, seja pela educação, seja pelo conflito. O fio da história está marcado pelas ações de Cosme Bento das Chagas, Esperança Garcia, Antônio Rebouças, João Cândido, José do Patrocínio, contradizendo os versos que cantam um Brasil brasileiro de democracia racial. Os movimentos revolucionários que nos inspiram, foram inspirados e fazem parte de um ciclo de intervenções políticas originadas do desejo de atingir o status quo de cidadãos conscientes de suas pertenças de sua responsabilidade para com a coletividade.

Todos os dias, histórias nascem e morrem de mobilizações que em suas táticas contam as emergências de práticas que desmitificam uma memória africana servil. Histórias que nos ensinam em seus espaços-tempos que os povos africanos nunca estiveram passivos à força do pensamento dominante que os pretendia em silêncio. Assim é a palavra na filosofia africana, nosso elo e fio condutor da sua própria história, do seu próprio conhecimento da existência. Narrar-se é espelhar nas sociedades e, na perspectiva africana, o conhecimento da realidade e a imaginação reflexiva sobre as compreensões das consequências das relações instituídas entre os seres da natureza, animados e inanimados (nas sociedades africanas tudo tem vida).

Os processos revolucionários no Brasil representam um coletivo de ações para tentar resolver os problemas na sociedade abrangente, em particular os provenientes dos preconceitos e das discriminações raciais, que os marginalizam no mercado de 
trabalho, no sistema educacional, político, social e cultural (PINTO apud DOMINGUES, 2008, p.101).

Grande parte dos grupos revolucionários concentrou sua ação simbólica sobre uma intenção política de união em torno de uma causa comum, e consequentemente, de fortalecer o negro para que se imponha perante a sociedade e expresse as suas reivindicações (PINTO, 1993, p. 28). O projeto ideológico do movimento negro foi de encontro à prosa e aos versos cantados e contados de uma democracia racial, quando o que há é a insistente reprodução e disseminação de estereótipos negativos ligados aos negros e imagens positivas associadas aos brancos. Combateram, por meio da reinvestigação dos processos históricos, a falácia de que no Brasil não havia problemas de raça - uma ausência de reconhecimento de que problemas de violência, discriminação e desigualdade de base étnica existem de fato entre nós. $\mathrm{O}$ fato de a ciência ter provado a inexistência de raça biológica não desfez nem aplacou os problemas decorrentes do conceito.

Por isso, o estudo das ações dos movimentos revolucionários tem sido tão fundamental para que fossem denunciadas as mais diversas mazelas que afetam as populações negras no âmbito do trabalho, da habitação, da educação e da saúde, tornando-se uma tribuna privilegiada para se pensar em soluções concretas para o problema do racismo.

Investigar os processos revolucionários é considerar que há muitas formas de militância e interação com a memória africana. $\mathrm{O}$ que não pode ser desconsiderado é que os movimentos negros nas mais diversas vertentes são a luta de sujeitos que visavam a um bem: o direito de cidadão, pois a República não previu inserções que beneficiassem as populações negras.

Os processos revolucionários têm buscado fazer um brainstorming ${ }^{1}$ ou uma reversão de imagens estereotipadas associadas às populações africanas e descendentes. Há um elo como conscientização, um Ubuntu, necessário como uma forma de fazer denúncia, pois o assunto negro, africanidades foi destorcido nas imagens do colonialismo e no escravismo criminoso. Tornou-se a questão dos donos da sua própria história, narrar e retornar à ancestralidade para narrar a epistemologia das populações negras.

\section{Para pensarmos a ancestralidade e o futuro}

Devido ao escravismo criminoso vigente por quase trezentos anos a sociedade brasileira flutua na ambiguidade em sermos parte da herança civilizatória africana e todas as suas formas e modificações, tanto no campo material como imaterial, nos diversos acervos das culturas das diversas regiões do país, mas também da forte negação desta cultura relegado por escravismo da mente em relação ao pensamento ocidental e a produção das formas antinegras. Realizamos no pensamento republicano a mais ampla política de institucionalização do racismo. Com fortíssimo trabalho das escolas de medicina da Bahia e do Rio de Janeiro as nossas mazelas eram produto de raça maldita e da improdutividade dos trópicos, fatores que precisavam ser sanados por uma ampla política de europeização e eliminação dos fatores africanos vigentes. Com base nos diagnósticos racistas se realizou ampla política pública de importação de mão de obra imigrante europeia. Além desta também se difundiu um pensamento de desqualificação das populações negras através da intervenção do Estado e eliminação

1Brainstorming (ou "tempestade cerebral"): técnica de dinâmica de grupo desenvolvida para explorar a potencialidade criativa de um indivíduo ou de um grupo - criatividade em equipe - colocando-a a serviço de objetivos pré-determinados. 
dos legados africanos. As culturas negras foram perseguidas e difamadas como parte do incivilizado na formação nacional a ser extirpado ou contido. Comungamos das propostas de Manuel Querino que pesquisou os diversos conhecimentos técnicos dos povos negros, atribuídos aos colonizadores europeus. Questionando a versão da história do Brasil que narra o colonizador, oriundo de uma zona temperada para se estabelecer em uma zona tropical, cujo clima e condições geográficas lhes eram desconhecidas. Para o referido teórico, os africanos e descendentes são o colono preto que se estabeleceu na América já conhecedor das técnicas para o trabalho a ser desenvolvido, como bom caçador, marinheiro, criador, extrator do sal, pastor, agricultor, mercador de marfim, minerador de ferro - há tempos o africano conhecia o trabalho da mineração, pois lá abundava o ouro, a prata, o chumbo, o diamante e o ferro (QUERINO, 1980).

Outrossim, Juliano Moreira, o grande médico negro baiano, um dos pais da psiquiatria nacional, foi um dos grandes opositores às teorias racistas e sobre o papel das populações pretas e pardas na formação nacional. Além deles, os movimentos negros e jornais do início do século vinte também realizaram amplos protestos e campanhas contra o racismo antinegro difundido na sociedade brasileira, determinando que os problemas apresentados por estas populações eram resultado exclusivo das condições sociais e ambientais em que viviam estas populações. Isto muito antes da existência dos trabalhos de Gilberto Freire que apesar de proclamados pela ciência eurocêntrica nacional, nada trouxe de progresso científico, apenas reforçou vários conceitos racistas sobre a inferioridade civilizatória da população negra. Prega-se que a inovação fantástica do referido livro é ter saído da ênfase na raça e ter mudado para cultura, o que também não foi avanço nenhum para a população negra, pois o que ocorreu foi a substituição da inferioridade pela raça pela inferioridade pela cultura (CUNHA JUNIOR, 2013).

Podemos afirmar que as posturas e simbologias destes protestos negros encontraram ampla representação e formas de síntese na vida e nas posturas de Nelson Mandela. Mas das ancestralidades e dos movimentos do início do século passado se fez uma renovação que teve, no combate ao apartheid na África do Sul, a renovação da esperança de empreendermos uma luta mais ampla contra o racismo e o colonialismo a roubo da dignidade dos seres humanos. A vida de Nelson Mandela é síntese exemplificadora de todos os nossos movimentos negros do século passado.

\section{Referências}

ALTUNA, Raul Luiz. Cultura tradicional Banto. São Paulo: Edições Paulinas. 2006. CUNHA JUNIOR, H. . NTU. Revista Espaço Acadêmico (UEM), v. 9, p. 81-91, 2010. . Críticas ao pensamento das senzalas e casa grande. Revista

Espaço Acadêmico, v.150, p. 1-17, 2013.

DIOP, Cheikh A. The african origin of civilization: myth or reality. New York, Lawrence Hill \& Company: 1973.

DOMINGUES, Petrônio José. Movimento negro brasileiro: história, tendências e dilemas contemporâneos. Revista de História (UFES), v. 21, 2008.

JAMES, C. L. R. Os jacobinos negros: Toussaint L'Ouverture e a revolução de São Domingos. Tradução de Afonso Teixeira Filho. São Paulo: Boitempo, 2000. 
KUHN, Thomas Samuel. A Estrutura das Revoluções Cientificas. São Paulo: Editora Perspectiva S. A., 1987.

OBENGA, Théophile. La Philosophie Africanine de la periode pharaonique. Paris: Harmattan, 1990

OLIVEIRA, Eduardo. Cosmovisão Africana no Brasil. Elementos para uma filosofia afrodescendente. Fortaleza: Ibeca, 2003.

Filosofia da Ancestralidade - Corpo e mito na filosofia da educação brasileira. Curitiba: Editora Gráfica Popular, 2007.

PINTO, Regina Tem. Movimento Negro e Educação do Negro: a ênfase na identidade. Caderno de Pesquisa, São Paulo, n.86, pág. 38, agosto, 1993.

QUERINO, Manuel Raimundo. O colono preto como fator da civilização brasileira. Afro-Ásia, n. 13, pp. 143-158.1980.

SILVA, Renata Aquino da. PROCESSOS IDENTITÁRIOS E PRÁTICAS CULTURAIS DE AFRO-BRASILEIROS: um estudo sobre os movimentos negros e os negros em movimento. 115f. Dissertação de Mestrado - Universidade do Estado do Rio de Janeiro, Programa de Pós-graduação em Educação da Faculdade de Educação, fevereiro 2010. 